\title{
Parametric Study and Design of a Slotted Microstrip Patch Antenna
}

\author{
Mohini Narendra Naik ${ }^{1}$, Dr. H.G.Virani ${ }^{2}$ \\ PG Student, Goa College of Engineering, Ponda, Goa, India ${ }^{1}$ \\ Professor, Goa College of Engineering, Ponda, Goa, India ${ }^{2}$
}

\begin{abstract}
In this paper, analyses and design of slotted Rectangular patch antenna for high speed wireless local area network at 5-6 GHz frequency has been done. A parametric study of the antenna has been carried out, to analyze and understand the effects of dimensional parameters. Main disadvantage of the microstrip patch antenna is its narrow bandwidth. However, in this paper slotting technique has been used to increase the bandwidth of the patch antenna. In this design, four slots are incorporated into Rectangular patch antenna. It gives fractional bandwidth of $0.202 \%$ with the center frequency of $5.4345 \mathrm{GHz} \& 0.334 \%$ with center frequency of $5.681 \mathrm{GHz}$. The antenna frequency band, with -10 $\mathrm{db}$ return loss covers the frequency range of 5.431-5.442 \&5.675-5.68 GHz. The design of patch antenna has been completed using IE3D software. The antenna is designed on $0.5 \mathrm{~mm}$ RT duroid 5880 substrate with dielectric constant of 2.2 and loss tangent 0.0004 operating at $5.25 \mathrm{GHz}$. A substrate of low dielectric constant is selected to obtain a compact radiating structure that meets the demanding bandwidth specification.
\end{abstract}

Keywords: Slotted patch antenna, Bandwidth, Return loss, WLAN.

\section{INTRODUCTION}

In each and every case, where transmitters and receivers are involved, there we require antennas. According to IEEE standard definition of terms for antennas, antenna is basically defined as the means of transmitting and receiving radio waves [1]. Applications in present-day mobile communication systems usually require smaller antenna size in order to meet the miniaturization requirements of mobile units. Thus, size reduction and bandwidth enhancement are becoming major design considerations for practical applications of microstrip antennas. Wireless local area networks (WLAN) are widely used worldwide. The IEEE $802.11 \mathrm{~b}$ and $802.11 \mathrm{~g}$ standards utilize the 2.4-GHz ISM band. The frequency band is license-free; hence the WLAN equipment will suffer interference from microwave ovens, cordless phone, Bluetooth devices and other appliances that use this same band. The 802.11a standard uses the 5-GHz band which is cleaner to support high-speed WLAN [3].

Microstrip patch antenna are widely used for many applications in recent wireless communications because of their light weight, low volume, ease in fabrication, low cost, etc. However microstrip antennas suffer from number of disadvantages. Narrow bandwidth is a serious limitation of these microstrip patch antenna. Different techniques are analyzed to improve the bandwidth such as increasing the substrate thickness, introducing parasitic element either in coplanar or stack configuration, and modifying the shape of a common radiator patch by incorporating slots. The last approach is particularly attractive because it can provide excellent bandwidth improvement and maintain a single-layer radiating structure to preserve the antenna's thin profile [1] [3].

In this paper slotted microstrip patch antenna is designed is designed at 5-6 GHz and parametric study is carried out to understand the effects of length and width of slots on the different parameters of the antenna. The antenna is designed on $0.5 \mathrm{~mm}$ RT duroid 5880 substrate with dielectric constant of 2.2 and loss tangent 0.0004 operating at $5.25 \mathrm{GHz}$.

The rest of the paper is organized as follows. Analysis of antenna design is explained in section II. Parametric study is given in section III. Experimental results are presented in section IV. Concluding remarks are given in section V.

\section{Antenna Design}

Rectangular patch antenna with four slots is designed at $5.25 \mathrm{GHz}$ frequency as shown in fig.1. Length (L) and Width (W) is calculated from set of equations [1]. A parametric study by varying the slot length (Lt) and slot width (Wt) is carried out.

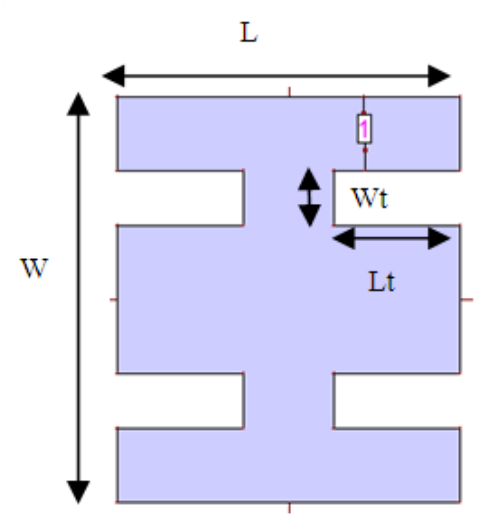

Fig. 1 Rectangular patch with slots at feed point $(4.5,9.4)$

Co-axial feed is used to fed this antenna because this feeding technique is much simpler and have least radiation losses in comparison to other feed technique like microstrip line feed, Aperture couple feed, proximity feed. In probe feeding we have chosen trial and error method to calculate the feed point where, desirable result is obtained is taken as final feed point $\left(\mathrm{X}_{0}, \mathrm{Y}_{0}\right)$. 


\section{III.PARAMETRIC STUDY}

Four slots of length (Lt) and width (Wt) are incorporated into patch antenna, which will still reduces the size of the antenna. The two parameters Lt, Wt are set as variable to study their effects on the resonant frequencies. The slot width (Wt) is varied from $1 \mathrm{~mm}$ to $5 \mathrm{~mm}$ keeping $\mathrm{Ls}=7 \mathrm{~mm}$. The effect of slot width is shown in fig 2 . When $\mathrm{Wt}=1 \mathrm{~mm}$, second resonant frequency mode cannot be excited. When $\mathrm{Wt}=3 \mathrm{~mm}$, second resonant frequency is excited but as width is increased fundamental resonant frequency mode cannot be excited. The slot length $(\mathrm{Lt})$ is varied from $1 \mathrm{~mm}$ to $7 \mathrm{~mm}$ keeping $\mathrm{Ws}=5 \mathrm{~mm}$. The effect of slot length is shown in fig 3 . When $\mathrm{Lt}=1 \mathrm{~mm}$ and $5 \mathrm{~mm}$, second resonant mode cannot be excited. As the length increases, the second resonant frequency mode is excited. Therefore slot width and slot length should be chosen perfectly to get two resonant frequencies.

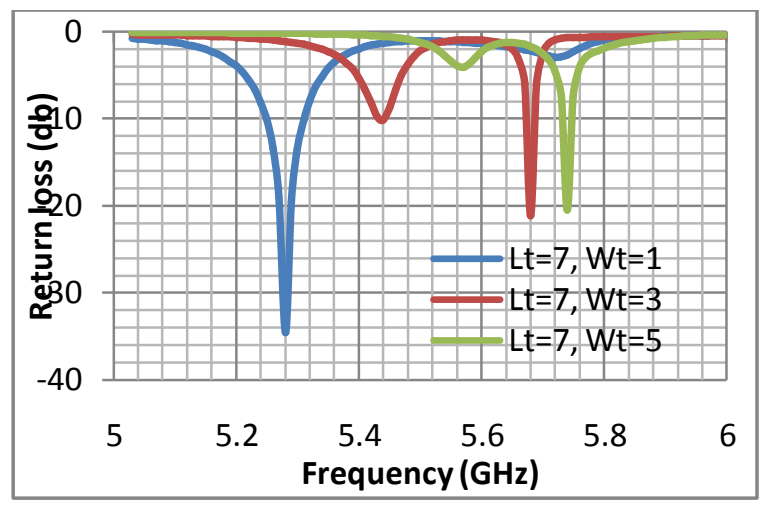

Fig. 2 Graph of Return loss v/s Frequency $(\mathrm{Lt}=7 \mathrm{~mm}$, Wt= $1 \mathrm{~mm}, 3 \mathrm{~mm}, 5 \mathrm{~mm}$ )

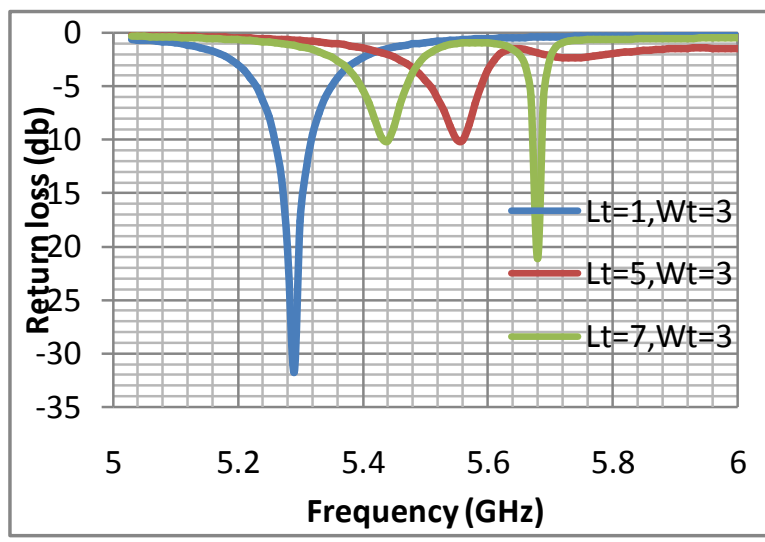

Fig. 3 Graph of Return loss v/s Frequency $(\mathrm{Lt}=1 \mathrm{~mm}, 3 \mathrm{~mm}, 7 \mathrm{~mm}, \mathrm{Wt}=$ $5 \mathrm{~mm})$

\section{RESULTS AND DISCUSSION}

For final design $\mathrm{Ls}=7 \mathrm{~mm}$ and $\mathrm{Ws}=3 \mathrm{~mm}$ is selected and design is simulated using IE3D software and fractional bandwidth is calculated. Simulated result is shown in fig 4. Slotted antenna gives impedance bandwidth of $4603 \mathrm{MHz}$ with the center frequency 5.55 GHz. The antenna frequency band, with $-10 \mathrm{db}$ return loss covers the frequency range of $5.4-5.68 \mathrm{GHz}$. The Radiation efficiency is about $82.14 \%$, Gain is $5.33 \mathrm{dBi}$ and Directivity is $7.69 \mathrm{dBi}$ at $5.4 \mathrm{GHz}$.

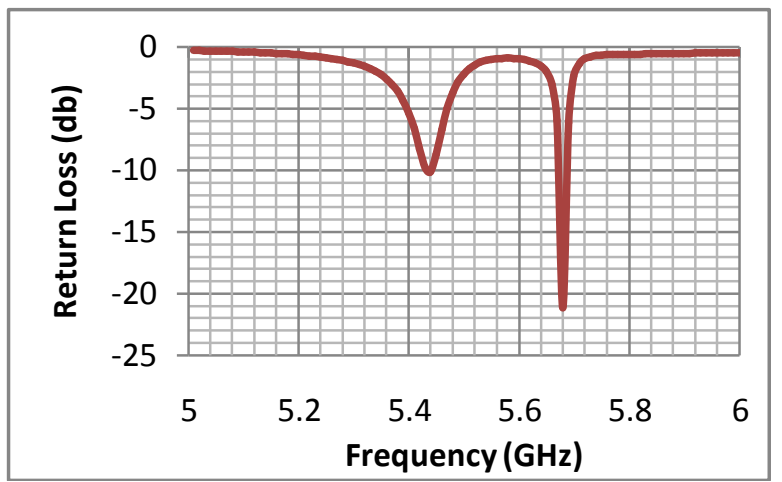

Fig. 4 Graph of Return loss v/s Frequency $(\mathrm{Lt}=7 \mathrm{~mm}, \mathrm{Wt}=3 \mathrm{~mm})$

\section{Conclusion}

In this paper, analysis and parametric study of slotted patch antenna has been done. Parametric study is carried out by varying Slot length and Slot width. It has been found that as width is increased fundamental resonant frequency mode cannot be excited. As the length increases, the second resonant frequency mode is excited. Therefore slot width and slot length should be chosen perfectly to get two resonant frequencies.

Finally, a slotted patch with $\mathrm{Ls}=7 \mathrm{~mm}$ and $\mathrm{Ws}=3 \mathrm{~mm}$ is selected and designed. It gives fractional bandwidth of $0.202 \%$ with the center frequency of $5.4345 \mathrm{GHz} \&$ $0.334 \%$ with center frequency of $5.681 \mathrm{GHz}$. Radiation efficiency is found to be around $82 \%$ which is very good. Gain and Directivity is also enhanced.

\section{ACKNOWLEDGMENT}

Author would like to thank our principal Dr. V. N. Shet and her guide Dr H. G. Virani for their constant support and encouragement. Last but not the least; author would like to thank her parents who were most co-operative throughout the course of this work.

\section{REFERENCES}

[1] G. B. Constantine A. Balanis , "Antenna theory Analysis and Design", 2nd edition, John Wiley and Sons, 2009.

[2] Fan Yang, Xui-Xia Zhang, Xioning Ye, and Yahya Rahmat-Sami, "Wideband E-shaped Patch Antenna for Wireless Communications," IEEE Transactions on Antennas and Propagation, vol. 49, no.7, July 2001.

[3] B.K. Ang and B.K. Chung, " A wideband E-shaped microstrip patch antenna for $5-6 \mathrm{GHz}$ wireless communications " Progress In Electromagnetics Research, PIER 75, 397-407, 2007.

[4] F. Yuehe Ge, Karu P. Esselle, Trevor S. Bird, "E-Shaped Patch Antennas for High-Speed Wireless Networks, " IEEE Transactions On Antennas And Propagation, vol. 52, no. 12, December 2004.

[5] Ahmed Khidre, Kai Fang Lee, Fan Yang, and Ate' Eisherbeni, "Wideband Circularly Polarized E-Shaped Patch Antenna for Wireless Applications," IEEE Antennas and Propagation Magazine, Vol. 52, No.5, October 2010.

[6] Kin-Lu Wong and Wen-Hsiu Hsu, "A Broad-Band Rectangular Patch Antenna With a Pair of Wide Slits," IEEE Transactions On Antennas And Propagation, VOL. 49, NO. 9, September 2001. 